American Journal of Applied Sciences 2 (12): 1610-1614, 2005

ISSN 1546-9239

(c) 2005 Science Publications

\title{
Cyclic Volta Metric Study of Alizarin Yellow R and Some Analogous Arylazo Compounds in DMF and in Aqueous Media
}

\author{
Hossnia Mohran \\ Department of Chemistry, Faculty of Science, South Valley University, 82524 Sohag, Egypt
}

\begin{abstract}
The Cyclic Voltammetry (CV) was used to investigate the electrochemical behavior of alizarin yellow $\mathrm{R}$ and some analogous arylazo compounds having almost the same central azo group. For this purpose, the substances chosen for the measurements are Alizarin Yellow R (AYR), Eriochrome Black T (EBT) and Sudan II (SUD II). The investigations were carried out at room temperature $(298 \mathrm{~K})$ in both aqueous solutions $\left(\mathrm{HClO}_{4}, \mathrm{NaClO}_{4}, \mathrm{KNO}_{3}\right)$ and non-aqueous medium (DMF), on the Hanging Mercury Drop Electrode (HMDE) and on the conventional Pt-disc electrode respectively. The CV results of AYR in aqueous solutions are characterized by a trace crossing that appears upon scan reversal, which is relatively rare. The CV experimental data together with their theoretical calculations for all compounds in DMF reveal unexpectedly irreversible radical anion step as a result of cis trans-isomerisation followed by reversible dianion process.
\end{abstract}

Key words: Cyclic voltammetry, electrochemical behavior, alizarin yellow R, analogous arylazo compounds, azo compounds

\section{INTRODUCTION}

Azo compounds are widely used in textile, printing, drugs, food-processing and cosmeting industries. They are also used extensively in laboratories as either $\mathrm{pH}$ indicators or biological stains. Lindstrom and Isaac investigated the crystalline calmagite and studied the sulphonation effects on azo dye metal-ion indicators ${ }^{[1]}$. Spectrophotometric procedures have been established for the quantitation of some drugs based on their reaction with some alizarins ${ }^{[2]}$.

EBT among appropriate indicators for $\mathrm{Ca}^{2+}$ and $\mathrm{Mg}^{2+}$ ions in biological experiments were distinguished and surveyed ${ }^{[3]}$.The photovoltaic and rectification properties of CdS-and $\mathrm{AgBr}$-sensitized EBT dye solar cells have been studied ${ }^{[4]}$. The manganese chelate with EBT adsorbed on the [HMDE] and the subsequent reduction current of the accumulated chelate was measured by stripping voltammetry ${ }^{[5]}$.The cis-trans photo-isomerization of EBT in the flat-plate collector system, which consists of endoergic photochemical reaction has been investigated ${ }^{[6]}$. EBT among different cationic and anionic dyes was found to be able to float galena and sphalerite minerals ${ }^{[7]}$. Batch and flowinjection determination of manganese in blood serum, based on the adsorptive reduction current peak of the EBT-manganese complex, was described ${ }^{[8]}$. The EBT in an alkaline solution was found to be appropriate as post-column reagent for the determination of rare earths by ion chromatography ${ }^{[9]}$. A procedure for the determination of manganese, which was complexed with EBT, in seawater by flow-injection preconcentration coupled to electrochemical atomic absorption spectroscopy was developed ${ }^{[10]}$. The voltammetry behavior of six azodyes (EBT and others) with various structures of the interface circuit and substituents in $\mathrm{O}, \mathrm{O}$-positions and their rare earth complexes was studied in detail ${ }^{[11]}$.

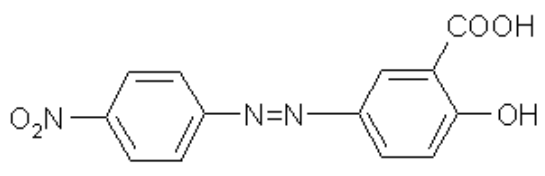

1

Alizarin Yellow R

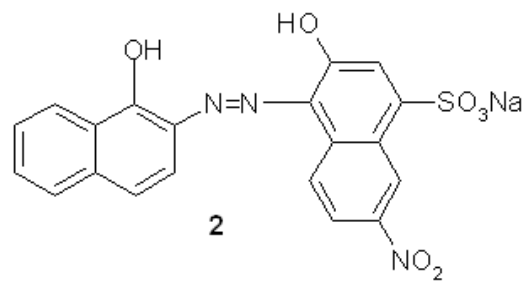

Eriochrome Black T

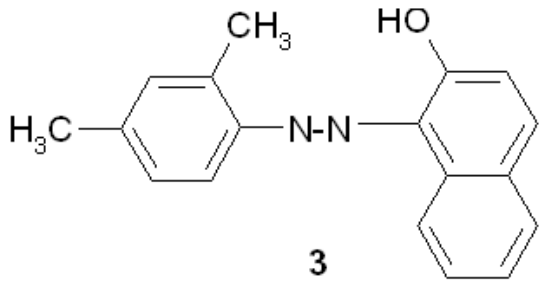

Sudan II

Corresponding Author: Hossnia Mohran, Chemistry Department, Faculty of Science, South Valley University, 82524 Sohag, Egypt 
Recently, sensitive and accurate spectrophotometric methods for the determination of nifedipine in pharmaceutical formulations have been developed. The methods are based on the formation of ion-pair complexes of the amino derivative of the drug with EBT and/or other azodyes ${ }^{[12]}$. A developed liquid chromatography-electrospray-tandem mass spectroscopy method for the simultaneous determination of sudan II among the other sudan compounds $^{[13]}$.

In all these treatments, little or no attention is given to the electrochemical investigation of the arylazo systems under investigation. The goal of this work was to use the cyclic voltammetry technique shed some light on the electrochemical responses characterizing these compounds.

\section{MATERIALS AND METHODS}

Reagent-grade $\mathrm{N}, \mathrm{N}$-dimethylformamide was further purified and dried according to a previous recommended method $^{[14]}$. Tetrabutylammonium hexaflourophosphate $\left(\mathrm{TBAPF}_{6}\right)$ obtained from FLUKA was recrystallised twice from pure ethanol and vacuum dried at $120{ }^{\circ} \mathrm{C}$. Aqueous electrolytes have been prepared using also reagent-grade chemicals and were diluted to proper concentrations with bidistilled water. Alizarin Yellow R.R.A.L. and Sudan II were a Prolabo products whereas Eriochrome Black T was a Sigma product and all were used as delivered.

For the purposes of carrying out electrochemical measurements in superdry media, a type of cell was used, which was described elsewhere ${ }^{[15]}$. In this cell, three electrodes are used; the working is either a platinum disc $(\mathrm{Pt})$ or a metrohm EA 290 hanging mercury drop electrode [HMDE]. A platinum wire is used as an auxiliary electrode. The reference electrode is an $\mathrm{Ag} / \mathrm{AgCl}$ where its potential is calibrated after each experiment against the reversible oxidation peak of ferrocene. The saturated calomel electrode (SCE) was used as the reference electrode in aqueous media. An EG\&G Princeton Applied Research, with a computer controlled 273A Potentiostat/Galvanostat as the hardware and the Model 270/250 Research Electrochemical Software to perform the desired signals. The cyclic voltammetric data were obtained on a HEWLETT PACKARD ColorPro plotter or on an EPSON FX-850 printer.

\section{RESULTS AND DISCUSSION}

Alizarin yellow R (AYR): Figure 1a shows the cyclic voltammogram for the reduction of $5.57 \mathrm{mM}$ of (AYR) in DMF containing $0.1 \mathrm{M} \mathrm{TBAPF}_{6}$ on the Pt-disc electrode. The formation of the radical anion of (AYR) ${ }^{-}$ at $\sim \mathrm{E}_{\mathrm{pc}}=-0.433 \mathrm{~V}$ is obviously irreversible, however the wave is observed as a small shoulder in the forward scan and it could not be detected in the reverse one.

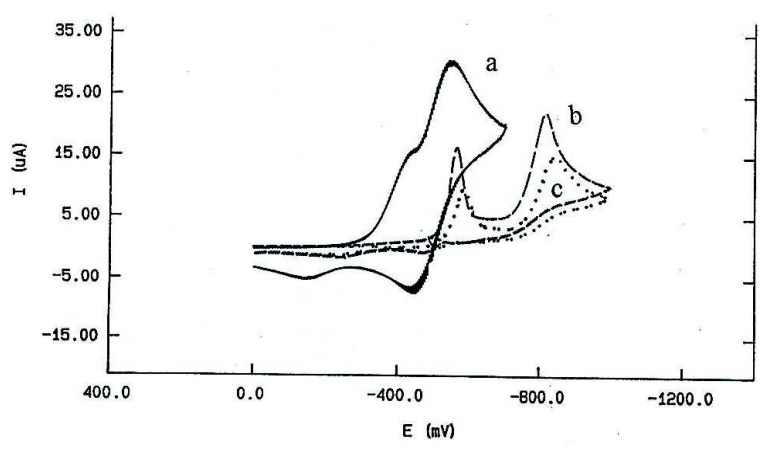

Fig. 1: Cyclic voltammograms of the electroreduction of Alizarin Yellow R (AYR) at $298 \mathrm{~K}$ for: a) $5.57 \mathrm{mM}$ in DMF/0.1 M TBAPF 6 on the Pt-disc electrode at potential scan rate $=200 \mathrm{mV} / \mathrm{s}, \mathrm{b}$ ) $1.5 \mathrm{mM}$ in $0.3 \mathrm{M} \mathrm{NaClO}_{4}$ on the [HMDE] at potential scan rate $=300 \mathrm{mV} / \mathrm{s}$ and $\mathrm{E}_{\lambda}=-1.0 \mathrm{~V}$ vs. SCE, c) $2.5 \mathrm{mM}$ in $0.3 \mathrm{M} \mathrm{KNO}_{3}$ on the [HMDE] at potential scan rate $=100 \mathrm{mV} / \mathrm{s}$ and $\mathrm{E}_{\lambda}=-1.0 \mathrm{~V}$ vs. SCE

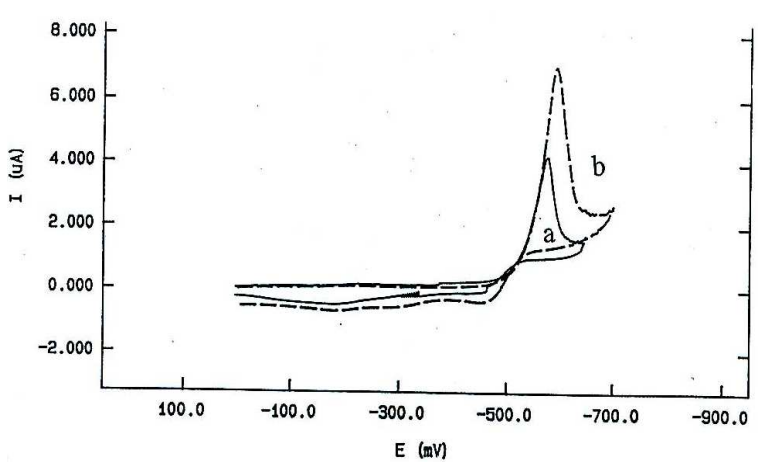

Fig. 2: a) single sweep cyclic voltammogram of 1.5 $\mathrm{mM}$ (AYR) in $0.3 \mathrm{M} \mathrm{NaClO}_{4}$ on the [HMDE] at $298 \mathrm{~K}$, potential scan rate: $100 \mathrm{mV} / \mathrm{s}$ and $\mathrm{E}_{\lambda}$ $=-0.650 \mathrm{~V}$ vs. SCE, b) single sweep cyclic voltammogram of $2.5 \mathrm{mM}$ (AYR) in $0.3 \mathrm{M}$ $\mathrm{KNO}_{3}$ on the [HMDE] at $298 \mathrm{~K}$, potential scan rate: $100 \mathrm{mV} / \mathrm{s}$ and $\mathrm{E}_{\lambda}=-0.700 \mathrm{~V}$ vs. $\mathrm{SCE}$

The peak corresponding to the building of the dianion of the molecule (AYR) ${ }^{2-}$ is clearly reversible at $\mathrm{E}_{1 / 2}=-0.490 \mathrm{~V}$ vs. $\mathrm{Ag} / \mathrm{AgCl}$ with a peak separation of $\Delta \mathrm{E}=100 \mathrm{mV}$, which is greater than the theoretical predicted value for a reversible one-electron transfer process. The unusual behavior of the peak separation can be ascribed to that a chemical reaction proceeding the charge transfer process, where the behavior is corresponding to an ECE mechanism. The chemical reaction is concluded to be a cis-trans isomerism around the $-\mathrm{N}=\mathrm{N}$ - of the dye molecule. The trans isomer is generally the more stable and the activation energy for the conversion is sufficiently low that the cis-isomer is generally not seen ${ }^{[16]}$. 


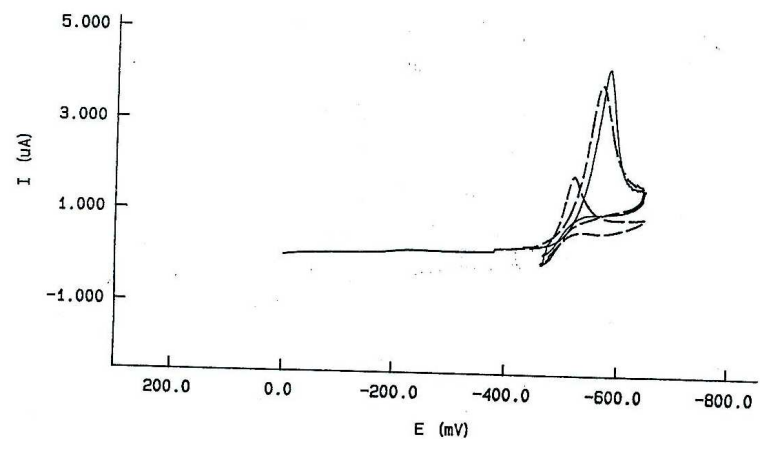

Fig. 3: Multisweep cyclic voltammogram of $1.5 \mathrm{mM}$ (AYR) in $0.3 \mathrm{M} \mathrm{NaClO}_{4}$ on the [HMDE] at $298 \mathrm{~K}$, scanned between -0.45 and $-0.650 \mathrm{~V}$ vs. SCE, potential scan rate: $100 \mathrm{mV} / \mathrm{s}$

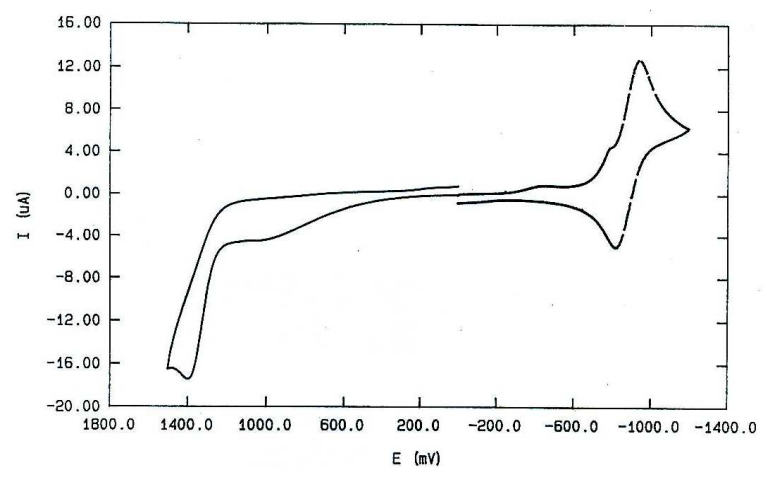

Fig. 4: Cyclic voltammograms of both the oxidation (scan rate $=100 \mathrm{mV} / \mathrm{s}$ ) and the reduction (scan rate $=200 \mathrm{mV} / \mathrm{s}$ ) of $1.51 \mathrm{mM}$ of Sud II in $\mathrm{DMF} / 0.1 \mathrm{M} \mathrm{TBAPF}_{6}$. scan rate: $100 \mathrm{mV} / \mathrm{s}$, $\mathrm{T}=298 \mathrm{~K}$ on the Pt-disc electrode

A behavior may observe from its cyclic response. The voltammetric behavior of (AYR) in protic solvents $\left(0.3 \mathrm{M}\right.$ of both $\mathrm{NaClO}_{4}$ and $\left.\mathrm{KNO}_{3}\right)$ are presented in the curves $1 \mathrm{~b}$ and $1 \mathrm{c}$ respectively. In this case, the anion radical formation of alizarin yellow and its subsequent electroreduction at $\mathrm{E}_{\mathrm{pc}}=-0.816 \mathrm{~V}$ in $\mathrm{NaClO}_{4}$ and $\mathrm{E}_{\mathrm{pc}}=$ $-0.843 \mathrm{~V}$ in $\mathrm{KNO}_{3}$ solutions, are clearly irreversible, which is documented by several overlapping waves on the reverse scan. From these observations and previous conventional polarographic study of analogous compound to those under investigation ${ }^{[17]}$, it was concluded that these compounds in protic media undergo the general reduction scheme as follows:

i. $\quad \mathrm{N}=\mathrm{N}-\left(\right.$ Arylazo) $+2 \mathrm{e}+2 \mathrm{H}^{+} \longleftrightarrow-\mathrm{NH}-\mathrm{NH}-$

ii. NH-NH- $+2 \mathrm{e}+2 \mathrm{H}^{+} \leftarrow-\mathrm{NH}_{2}+-\mathrm{NH}_{2}$ (corresponding amine)

As already demonstrated by the behavior of (AYR) in aqueous solutions, the two reduction peaks are clearly characteristic for an ECEC mechanism that each peak involves the gain of two electrons from the electrode, followed by the subsequent acceptance of two protons of the solution as a chemical step.

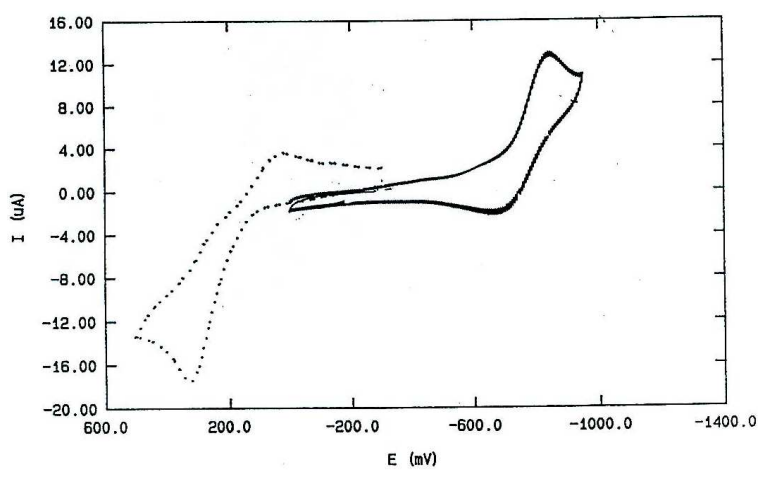

Fig. 5: Cyclic voltammograms of both the oxidation and the reduction (scan rate $=100 \mathrm{mV} / \mathrm{s}$ for both) of $5.3 \mathrm{mM}$ EBT in DMF/0.1 $\mathrm{M} \mathrm{TBAPF}_{6}$ on the Pt-disc electrode at $298 \mathrm{~K}$

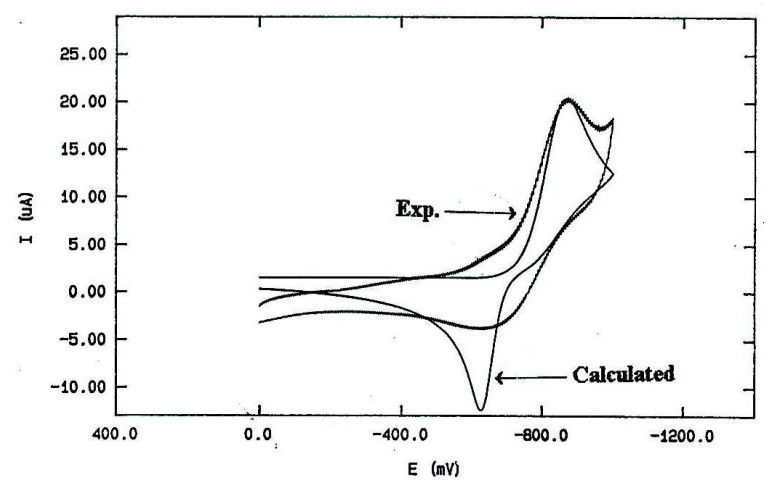

Fig. 6: Theoretical calculation for the electroreduction of $5.3 \mathrm{mM}$ of EBT in DMF/0.1 M TBAPF 6 using quasi-reversible 2e-transfer model

A typical cyclic voltammograms representing the reduction of (AYR) in $\mathrm{NaClO}_{4}$ and $\mathrm{KNO}_{3}$ are given in Fig. $2 a$ and $2 b$ respectively. In the forward scan a large cathodic peak is observed, followed in the reverse scan by two smaller oxidation waves. A striking feature of this behavior is the trace crossing that appears upon scan reversal, indicating that a reducible species is produced during the anodic scan. In a multisweep experiment scanned between -0.45 and $-0.65 \mathrm{~V}$ vs. SCE (Fig. 3), a new reduction wave with a cathodic peak potential $\left(\mathrm{E}_{\mathrm{pc}}=-0.567 \mathrm{~V}\right)$ appears in the second cathodic scan and becomes good distinguishable in the third scan at $\mathrm{E}_{\mathrm{pc}}=-0.519 \mathrm{~V}$ vs. SCE. Simultaneously, the original cathodic waves at $E_{p c}=-0.563 \mathrm{~V}$ and $E_{p c}=-$ $0.584 \mathrm{~V}$ (in $\mathrm{NaClO}_{4}$ and $\mathrm{KNO}_{3}$ respectively), decrease in height and gradually disappear. In the same experiment, in addition to the unusual trace crossing effect, an isopotential point (IPP) at $\sim-0.530 \mathrm{~V}$ is observed. This phenomenon can be interpreted in analogy to an isobestic point. It reveal that the transformation of an electroactive species into another one occurs quantitatively with side reactions ${ }^{[18]}$. Although the isopotential point has been known for 
adsorbed species and polymer films, only recently it has been described for systems where both reactants and products are in solution ${ }^{[19]}$. As already demonstrated by the behavior of AYR in DMF, the large reduction wave of AYR in aqueous solutions is characteristic for an ECE mechanism that involves as a chemical step the cis-trans isomerization of the dye molecule.

\section{Electrochemical studies of 1-(2,4- dimethylphenylazo)-2-naphthol (Sudan II): The} electrochemical reduction of arylazo compounds was motivated by analogies with the metabolic processes that they undergo in the human organism ${ }^{[17]}$. It was concluded that the mechanism of their electrochemical behavior depends substantially on the nature of the attached aryl moiety ${ }^{[17]}$.

Cyclic voltammograms of the first reduction step obtained for Sudan II in superdry DMF at a Pt disk electrode clearly resample to that observed for ARY in the same medium. As Fig. 4 depicts, the reduction voltammogram consists simply of two waves, the first of which is a small irreversible one, whereas the second is an ideal reversible peak. Again, a behavior corresponds to an ECE-mechanism where the cis-trans rotation of the dye compound is the proposed chemical follow-up reaction. The difference in the magnitudes of the first and second peak attests to the relatively slow character of the first charge transfer step as a result of the compound rotation. On the other hand, the large difference in the peak-separation value of the second wave $\left(\Delta \mathrm{E}_{\mathrm{p}}\right)$ relative to the expected value for reversible 1e-transfer again is consistent with the expected preceding cis-trans isomerization of the molecule.

The oxidation cyclic voltammetric response of sudan II in $\mathrm{DMF}^{\mathrm{TBAPF}} 6$ at $298 \mathrm{~K}$ on the Pt-disk electrode, is characterized by also a small irreversible peak followed by a large quasi-reversible to irreversible wave at $\mathrm{E}_{\mathrm{pa}}=1.393 \mathrm{~V}$ vs. SCE. The foregoing conclusion ( ECE-mechanism, where the cis-trans isomerization is the follow-up chemical reaction) proposed for reduction can not be completely applied in this case. The probability that the di-cation of (Sud II) ${ }^{2+}$ undergoes some sort of decoposion is highly possible, leading to an ECEC-mechanism. However, when theoretical calculation using quasi-reversible 2e-transfer model for the oxidation of Sudan II, the results seemed to verify the proposed chosen theoretical model. The voltammetric measurements of the molecule (Sud II) in $0.3 \mathrm{M}$ of both $\mathrm{NaClO}_{4}$ and $\mathrm{KNO}_{3}$ at the hanging mercury drop electrode [HMDE] proceed obviously irreversible. The cathodic reduction voltammogram of the compound consists of a large irreversible wave at $\mathrm{E}_{\mathrm{pc}}=-0.680 \mathrm{~V}$, followed by a smaller reversible peak at $\mathrm{E}_{1 / 2} \approx-1.10 \mathrm{~V}$ vs. SCE. The obtained results of Sudan II in aqueous solutions, although the molecule has a limited solubility in protic media (maximum of 0.5 $\mathrm{mM}$ ), are consistent with the foregoing findings for the reaction route and confirm previous conclusion ${ }^{[17]}$.

Eriochrome black T (EBT): Additional features of the arylazo redox systems were clarified by the electrochemical study of (EBT). Both the cathodic reduction and the anodic oxidation of (EBT) in DMF/0.2 $\mathrm{M} \mathrm{TBAPF}_{6}$ on the Pt disk electrode carried out at $298 \mathrm{~K}$ are displayed in Fig. 5. At a first sight, the electrochemistry of EBT in $\mathrm{DMF}^{\mathrm{T}} \mathrm{TBAPF} \mathrm{F}_{6}$ differs slightly from that of AYR and Sud II. The reduction voltammogram seems to be consist of only one quite reversible wave at $\left(\mathrm{E}_{\mathrm{pc}}=-0.845 \mathrm{~V}\right.$ vs. $\left.\mathrm{Ag} / \mathrm{AgCl}\right)$, whereas that corresponds to the formation of the radical cation $(\mathrm{EBT})^{+\cdot}$ of the compound which is observed at $\mathrm{E}_{\mathrm{pa}}=+0.327 \mathrm{~V}$ vs. $\mathrm{Ag} / \mathrm{AgCl}$ is clearly thermodynamically less stable than the corresponding radical anion. Theoretical calculations for the cathodic reduction of (EBT), reveal that the process is quasireversible with 2-electron transfer gained by the electrode from EBT coupled to a follow up chemical reaction confirming the proposal of an ECEmechanism.

The electrochemical investigation of eriochrome black $\mathrm{T}$ in aqueous solutions is not very inconvenient due to its limited solubility. The cyclic voltammogram of the cathodic reduction of $0.36 \mathrm{mM}$ of (EBT) in 0.3 $\mathrm{M} \mathrm{KNO}_{3}$ is characterized by a large irreversible peak at about $\mathrm{E}_{\mathrm{pc}}=-1.400 \mathrm{~V}$ vs. SCE, which is very similar to that observed in $0.3 \mathrm{M} \mathrm{NaClO}_{4}$ solution. This implies that the wave may represent the same proposed reaction route for AYR and Sud II. The main differences in the voltammetric behavior between the three compounds in this study result substantially from the effects of the attached aryl moiety ${ }^{[17]}$. This probably led to conclusion that the electronic and the Columbic interactions between the charges in case of AYR and Sud II are greater than those in case of the corresponding EBT.

\section{REFERENCES}

1. Lindstrom, F. and A.E. Womble, 1973. Locating the more acidic hydroxyl group on dihydroxy compounds. Talanta, 20: 589-597.

2. Shama, S. and A. Amin, 2004. Spectrophotometric microdetermination of nefopam, mebevrine and phenylpropanolamine hydrochloride in pharmaceutical formulations using alizarins. Spectrochimica Acta A, 60: 1769-1774.

3. Durham, A.C.H. and J.M. Walton, 1983. A survey of the available colorimetric indicators for $\mathrm{Ca}^{2+}$ and $\mathrm{Mg}^{2+}$ ions in biological experiments. Cell Calcium, 4: 47-55. 
4. Sharma, G.D., D.C. Dube and S.C. Mathur. 1985. $\mathrm{CdS}$ and $\mathrm{AgBr}$ sensitized Erichrome black T (EBT) dye cells. Solar Cells, 15: 189-197.

5. Wang, J. and J. Mahmoud, 1986. Stripping voltammetry of Manganese based on chelate adsorption at the hanging mercury drop electrode. Anal. Chimica Acta, 182: 147-155.

6. Naman, S.A., S.A. Said and F.M. Hussein, 1988. Photochemically assisted solar energy storage using eriochrome black $\mathrm{T}$ in Solar flat collector. Solar Energy, 41: 241-246.

7. Sengupta, D.K., S.K. Roy and S.C. Sircar, 1988. Flotation of sulphide minerals by anionic and cationic dyes. Inter. J. Min. Proces., 23: 151-155.

8. Goldik, R., C. Yarnitzky and M. Ariel, 1990. determination of magnesium in blood serum using a flow-injection system with a potential-scanning electrochemical detector equipped with a thin-film deaerator. Anal. Chimica Acta, 234: 161-166.

9. Sarzanini, C., O. Abollino and E. Mentasti, 2001. Flow-injection preconcentration and electrothermal atomic absorption spectrometry determination of manganese in seawater. Anal. Chimica Acta, 435: 343-350.

10. Dubenska, L., H. Lerytska and N. Poperechna, 2001. Polarographic investigation of reduction process of some azodyes and their complexes with rare earths. Talanta, 54: 221-231.

11. Rahman, N., N.A. Khan and S.N. Azmi, 2004. Extractive spectrophotometric methods for the determination of nifedipine in pharmaceutical formulations using bromocresol green, bromophenol blue, bromothymol blue and eriochrome black T. IL Farmaco, 59: 47-54.

12. Gettar, R.T., E.A. Gautier, R.E. Servant and D.A. Batistoni, 1999. Eriochromblack $\mathrm{T}$ as a postcolumn reagent for the ion chromatographic determination of rare earths. J. Chromatography, A, 855: 111-119.
13. Calbiani, F., M. Careri, L. Elviri, A. Mangia, L. Pistara and I. Zagnoni, 2004. Development and inhouse validation of a liquid chromatographyelectrospray-tandem mass spectroscopy method for the simultaneous determination of Sudan I, Sudan II, Sudan III and Sudan IV in hot chilli products. J. Chroma. A, 1042: 123-130.

14. Coetzee, J.F., 1982. Recommended Methods for Purification of Solvents. Pergamon, Oxford.

15. Rashwan, F., 1988. AC-voltammetrische und cyclovoltammetrische Untersuchungen an mehrstufigen Redoxsystemen. Doctoral Dissertation, Freiburg University, West Germany.

16. Streitwieser, A. and Jr.C.H. Heathcock, 1985. Introduction to Organic Chemistry. Third Edn. Macmillan Publishing Company, New York.

17. De La L.I., Cruz Yaguez, J.M. Pingarron Carrazon and L.M. Polo Diez, 1986. Polarographic study of 1-(2,4-dimethyphenylazo)-2-naphthol (Sudan II) in hydrochloric medium. 1Electrochimica Acta, 31: 119-121. and the references contained therein.

18. Hinkelmann, K., J. Heinze, H.T. Schacht, J.S. Field and H. Vahrenkamp, 1989. "Two-Step" Electron Transfer and Mechanism of Electrochemically Induced Reactions of the $\mathrm{MeCCO}_{3}(\mathrm{CO})_{9}$ Cluster and its Phosphine Derivatives. J. Am. Chem. Soc.; 111 No. 14: 5078-5091. and references therein.

19. Heinze, J., M. Dietrich, K. Hinkelmann, K. Meerholz and F. Rashwan, 1989. Der "Zweielectronentransfer", ein facettenreicher Mechanismus. DECHEMA-Monog. 112: 61-74. and references listed therein. 